\title{
DOUTORES E DOUTORANDOS EM ENFERMAGEM: MOTIVOS DO MESTRADO EM OUTRAS ÁREAS
}

\author{
Victória Secaf* \\ Paulina Kurcgant**
}

SECAF, V.; KURCGANT, P. Doutores e doutorandos em enfermagem: motivos do mestrado em outras áreas. Rev. latino-am.enfermagem, Ribeirão Preto, v. 7, n. 1, p. 5-10, janeiro 1999.

Na Pós-Graduação em Enfermagem no Brasil, existem 37 doutores/doutorandos (em Enfermagem) que fizeram Mestrado em outra área. Foram obtidos depoimentos de 28 integrantes desse grupo no que se refere aos motivos da escolha, sua inserção no Programa frequentado e as sugestões para outros enfermeiros em idêntica situação à sua e para as Escolas de Enfermagem. A opção, embora determinada por circunstâncias diversas, constituiu uma experiência enriquecedora para os sujeitos e integra a história dos cursos/programas de Pós-Graduação de Enfermagem no país.

UNITERMOS: programa de pós-graduação, enfermagem, ensino

\section{CONSIDERAÇÕES INICIAIS}

$\mathrm{Na}$ década de 70 os programas/cursos de Mestrado em Enfermagem eram apenas nove e tinham como grande demanda os docentes de Escolas de Enfermagem. Desta forma os processos seletivos nessas Escolas pioneiras atendiam à demanda interna (seguimento de carreira docente) e para a externa, a demanda era constituída por enfermeiros assistenciais.

As décadas de 80 e 90 foram marcadas, no Brasil, pelo desenvolvimento de cursos/programas de Doutorado em Enfermagem.

Constata-se que a região Sudeste não só foi a pioneira na criação dos cursos de Pós-Graduação em Enfermagem como ocupa, neste final do milênio, posição de liderança no atual contexto. (CASTRO et al., 1989 \& ALMEIDA, 1993).

Por outro lado, a necessidade de ser portador, pelo menos, do título de Mestre passou a ser uma exigência institucional e não apenas "a meta profissional" dos docentes de Enfermagem como refere FRAGA (1994) e CASTRO et al. (1989).

Ainda, segundo FRAGA (1994); ALMEIDA (1993) e ONOFRE (1990) para os enfermeiros assistenciais de qualquer região do país, não existe uma política institucional consistente que estimule e beneficie os que se propõem a fazer curso de Pós-Graduação.

Mesmo diante desta realidade, a maioria dos docentes e muitos enfermeiros assistenciais têm procurado cursar programas de Pós-Graduação em Enfermagem em diferentes regiões do País (ALMEIDA, 1993).

Entretanto, a distribuição geográfica e o quantitativo dos cursos/programas de Mestrado em Enfermagem têm impedido que muitos enfermeiros possam ter acesso aos mesmos.

O descompasso entre a demanda e o oferecimento compatível de cursos levou muitas profissionais a buscarem cursos de Mestrado em outras áreas que não a de Enfermagem.

Por outro lado, é válido questionar se o interesse em Programas de Mestrado que não os de Enfermagem, poderia estar vinculado à busca de um saber existente nas áreas de interface da Enfermagem com outras ciências e mesmo a necessidade de obter a complementaridade àquele saber.

Estes teriam sido os motivos pelos quais os enfermeiros procuraram cursar Mestrado em outras áreas?

O resgate da história sempre priorizou eventos que envolviam maiorias e nas publicações da PósGraduação em Enfermagem já foram assinalados muitos desses momentos.

A trajetória resgatada na história de PósGraduação de Enfermagem mostra a existência de três grupos distintos: os enfermeiros, grupo majoritário, que

\footnotetext{
* Professora Doutora da Escola de Enfermagem da Universidade de São Paulo

** Professora Titular da Escola de Enfermagem da Universidade de São Paulo
} 
cursou Mestrado e Doutorado na área de Enfermagem; os que fizeram Mestrado e Doutorado em outra área e o terceiro grupo é constituído por enfermeiros que cursaram o Mestrado em outra área e posteriormente procuraram cursar Doutorado na área de Enfermagem.

Inúmeras questões podem ser levantadas para explicar o porque dos colegas desse último grupo terem procurado outra área e posteriormente cursarem o Programa de Doutorado em Enfermagem.

Pretendemos assinalar a existência e os motivos desse grupo minoritário, que ainda não foi considerado mas que, sem dúvida, também faz parte dessa história. Assim, procuramos pesquisar “algo" sobre um determinado contingente de Doutores e Doutorandos em Enfermagem.

Não ter cursado Mestrado em Enfermagem pode ter sido pela não existência do referido Programa na sua cidade ou mesmo por fatores outros.

A centralização de cursos na região Sudeste do país que obrigaria, sem dúvida, os enfermeiros a deslocamentos distantes da sua cidade de origem para realização de cursos pode ser um deles (FRAGA, 1994).

Porém, decidir-se pela escolha de outro Programa, enfrentar a seleção com profissionais de outras áreas e mesmo concluir sua Dissertação, em temas paralelos à sua formação inicial, certamente foi um desafio.

"Ouvir" cada um desses sujeitos que enfrentou esse desafio pode contribuir para o resgate da trajetória da Pós-Graduação em Enfermagem.

\section{PERCURSO METODOLÓGICO}

A ocorrência de vários casos semelhantes (mestrado em outra área que não a de Enfermagem) suscitou indagações, despertou nosso interesse, e daí partimos em busca de respostas.

Descobrir onde estão ou estavam essas pessoas constituiu a fase preliminar bem como elaborar o instrumento a ser adotado no estudo permitiria a obtenção de dados para análise da situação-problema.

Para tanto, a pesquisa quanti-qualitativa foi escolhida e a população (doutores/doutorandos com Mestrado em outra área que não a de Enfermagem) constituiu a fonte de dados.

\subsection{População}

Para tanto, foram identificadas as Escolas de Enfermagem que possuíam cursos de Doutorado em Enfermagem no Brasil.

Assim, na fase preliminar, ( $2^{\circ}$ semestre de 1995), por correspondência, obtivemos desses Cursos/ Programas, a relação numérica de doutores ou doutorandos com título de Mestre em área diversa da Enfermagem. Os dados solicitados foram: nome completo, endereço atualizado, ano de ingresso no Doutorado e qual área de Mestrado cursada.

As cinco relações obtidas totalizaram 37 doutores/doutorandos que preenchiam os requisitos exigidos para o estudo. O Quadro 1 demonstra as diferentes opções de Mestrado destes doutores e doutorandos.

Cabe esclarecer que o total de cursos/programas ultrapassa o total de Escolas de Enfermagem que mantêm Doutorado, pois algumas delas têm mais de um curso de Doutorado ou mesmo algum Programa de Expansão.

A população localizada corresponde à totalidade e a representatividade do grupo é significativa sob o ponto de vista numérico, pois obtivemos resposta de 28 profissionais, doutores e doutorandos, no final de 1995 e início de 1996.

\section{Quadro 1 - Distribuição das áreas de mestrado segundo opção dos doutores e doutorandos}

\begin{tabular}{|c|c|c|c|c|c|c|c|c|c|c|c|c|}
\hline Áreas & Educaçäo & $\begin{array}{l}\text { Saúde } \\
\text { Públical } \\
\text { Coletiva }\end{array}$ & Adrinistr. & Psicol. & $\begin{array}{c}\text { Med. } \\
\text { Veterinánia }\end{array}$ & Antropol. & $\begin{array}{l}\text { Ciências } \\
\text { B iol. I } \\
\text { Genét' }\end{array}$ & $\begin{array}{c}\text { Extensão } \\
\text { Rural }\end{array}$ & $\begin{array}{l}\text { Filosofia } \\
\text { da Educ. }\end{array}$ & Fisiologia & Nutrição & TOTAL \\
\hline FF1* & & & & & & & & & & & & \\
\hline $\begin{array}{l}\mathrm{EL1} \\
\mathrm{EE} 2\end{array}$ & $\begin{array}{l}08 \\
05\end{array}$ & -01 & $\begin{array}{l}01 \\
-\end{array}$ & $\overline{0}$ & 5 & O1 & $\overline{0}$ & $\begin{array}{l}01 \\
01\end{array}$ & 5 & - & - & $\begin{array}{l}12 \\
09\end{array}$ \\
\hline $\mathrm{EE} 3$ & 02 & 01 & - & - & - & - & - & - & - & - & - & 03 \\
\hline $\mathrm{EE} 4$ & 02 & - & - & - & - & - & - & - & - & - & 01 & 03 \\
\hline EES & 01 & 02 & 02 & - & 02 & - & 01 & - & 01 & 01 & - & 10 \\
\hline TOTAL & 18 & 04 & 03 & 02 & 02 & 01 & 02 & 02 & 01 & 01 & 01 & 37 \\
\hline
\end{tabular}

\subsection{Instrumento}

Para elaboração do instrumento de coleta de dados optou-se pelo questionário, precedido por uma carta, enviada pelo correio, pela facilidade de endereço atual de cada sujeito do estudo como possibilidade do mesmo 
expressar-se por escrito e sem a interferência dos pesquisadores (Anexo 1).

Assim, pelo roteiro norteador buscava-se respostas aos motivos que levaram esses profissionais a cursar cursos/programas de Mestrado em outras áreas, bem como desvelar a percepção que esses profissionais têm a respeito dessa experiência.

\section{O PROCEDIMENTO E A ANÁLISE DOS ACHADOS}

Para se proceder à análise de conteúdo, as respostas foram lidas cuidadosamente, por várias vezes, até permitirem o resgate dos diferentes significados emergentes.

Questão 1. Motivos para a realização do mestrado

Nas respostas obtidas na questão 1 os motivos relatados pelos depoentes, para a realização do Mestrado em outra área, encontram-se na dimensão pessoal/ familiar, profissional e institucional.

Convém salientar que, mesmo sem ter sido perguntado aos doutores e doutorandos, a análise permitiu resgatar elementos contraditórios nos depoimentos e nos motivos que levaram os enfermeiros a fazerem PósGraduação. Além disso, emergem elementos incentivadores e bloqueadores nas dimensões acima citadas.

No tocante à dimensão pessoal (maioria da população do estudo feminino), os motivos foram bloqueadores, uma vez que o fato da profissional ser casada, ter filhos, seria impeditivo muitas vezes para freqüentar curso em outra cidade. As falas, a seguir, exemplificam esses motivos:

"impossibilidade no momento de me afastar da minha cidade"

“inexistência de pós-graduação em enfermagem no estado de..."

"inexistência do curso no estado de... e a dificuldade de sair por ser casada e ter filhos pequenos"

"dificuldade de afastamento da cidade onde residia por motivos econômicos".

Esse mesmo motivo, quando considerado na esfera institucional, isto é, a não existência de "programas de pós-graduação em enfermagem na própria cidade ou estado" também é bloqueador, por obrigar o deslocamento desses enfermeiros para outro local.

$\mathrm{Na}$ dimensão profissional constata-se que, embora relatados vários motivos bloqueadores, é evidente que os incentivadores sobressaem em número e qualidade como explicitado a seguir:
“.... pelas inquietações e questionamentos

e especialmente da insatisfação resultante frente à minha prática profissional enquanto docente"

“... dificuldade de ingresso nos programas de mestrado na área de enfermagem devido às exigências nos processos seletivos... estes critérios não são sempre rígidos em outros programas"

"buscar subsídios técnicos na área de humanas para a prática de enfermagem..." "prosseguimento a linha de especialização em saúde coletiva"

“conviver com profissionais de outras áreas poderia representar crescimento profissional e pessoal"

"por gostar da área de educação".

$\mathrm{Na}$ dimensão institucional, além dos motivos citados, cabe distinguir a organização onde o doutor/ doutorando trabalha, aquela onde realizou o Mestrado e as Escolas de Enfermagem que mantém curso de Mestrado em Enfermagem.

\section{Questão 2 - Inserção no mestrado}

Conforme demonstrado no Quadro 1, há diversificação das áreas de Mestrado escolhidas e resgata-se nas falas dos depoentes "convivência boa, tranqüila, harmoniosa”, "que ela (enfermeira) formava uma ponte entre as várias áreas".

Os sentimentos contraditórios aparecem decorrentes da manifestação de outros enfermeiros de que ele, mestrando, "estaria abandonando a profissão de enfermagem" por ter feito Mestrado em outra área.

Como dificuldades foram relatadas apenas "os vazios de conhecimento no que se refere a algumas áreas não estudadas por enfermeiras como por exemplo: administração financeira e contabilidade".

\section{Questão 3 - Percepção da experiência}

\subsection{No doutorado}

Os depoentes estrangeiros, e com Mestrado em outra área, em seu país de origem, referiram "choque cultural", "dificuldades em relação ao idioma" como significativos na experiência do doutorado em enfermagem.

Os depoentes brasileiros consideraram a experiência do Mestrado em outra área como possibilidade para "ampliar horizontes", "diversificar conhecimentos", e "ter perspectivas menos tecnicistas".

O "estar conciliada com a profissão e os colegas" foi a percepção posterior do doutorando que havia sido acusado de "ter abandonado a profissão". 
3.2. No Mestrado e na vida profissional

Do total dos 28 depoentes, fica evidente o quantitativo de Mestrado em Educação mesmo porque estes profissionais vivenciam o cotidiano na área de ensino em Escolas de Enfermagem ou no setor de Educação Continuada em instituições hospitalares.

Assim, as falas destes depoentes demonstram a correlação positiva entre o Mestrado escolhido e a área de atuação: "facilitar a atuação como docente", "na prática pedagógica", "nas discussões curriculares".

Além disso, o vivenciado no Mestrado possibilita, profissionalmente, "melhoria no trabalho em equipe", “análise da realidade vivida”, e “capacitação em cargos de chefia".

\section{Questão 4 - Sugestões}

\subsection{Para as Escolas de Enfermagem}

Nos depoimentos resgata-se que os sujeitos do estudo percebem as Escolas de Enfermagem em dois momentos: um deles refere-se às Escolas, quando oferecem programas de Pós-Graduação em Enfermagem tais como: "que os programas de pós-graduação sejam abertos a outros profissionais”, “que ocorra a interdisciplinaridade”, “que os programas deixem transparecer a preocupação com a educação e aspectos didáticos”.

Consideram ainda a necessidade de "fechar o campo de abrangência” e "aprofundar", "maior inserção em áreas como ciências sociais, filosofia e educação".

O outro momento refere-se à percepção que eles têm dos docentes das Escolas de Enfermagem e que coincide, muitas vezes, com as sugestões que dirigem a outro enfermeiro. As falas a seguir explicitam esse fato: "incentivar os profissionais, aproximar-se com a área da educação", "diversificar o leque de conhecimentos", "momentos de reflexão e debate".

\subsection{Para outros profissionais}

Nas sugestões específicas para os enfermeiros resgatam-se frases de incentivo, propostas que são traduzidas como: "enfrentar desafios"; "arriscar-se, expor-se à seleção"; "coragem para inovar"; "somos capazes"; "temos condições".

Em outras falas, ainda fica evidente a sugestão quanto à transcendência profissional do enfermeiro: "buscar conhecimento em outras áreas e correlacionar com a prática de enfermagem"; "buscar cursos que atendam suas necessidades"; “ampliar horizontes e enriquecer a área de enfermagem"; "enriquecimento profissional".

\section{CONSIDERAÇÕES FINAIS}

É válido concluir que o estudo de determinados grupos, mesmo minoritários, contribue para a construção da história. O valor de tais estudos é relevante se permitir que fatos/personagens que influíram no desenvolvimento da Enfermagem Brasileira, possam ser registrados.

Assim, a análise dos depoimentos desses doutores e doutorandos, que fizeram Mestrado em outra área que não a de Enfermagem, permitiu uma "nova" leitura da prática de enfermagem resultado esse, ainda "não registrado" em outros artigos sobre a Pós-Graduação da Enfermagem brasileira.

Essa opção, embora determinada por circunstâncias adversas, constituiu, como declarado pelos respondentes, uma experiência enriquecedora no âmbito pessoal e profissional.

\section{NURSING DOCTORS AND DOCTORAL STUDENTS: REASONS TO OBTAIN A MASTER DEGREE IN OTHER AREAS}

There are in Brazil only 37 nursing doctors and doctoral students who obtained the Master degree in other area. A set of questions - concerning the reasons of the choice, the enrolment in the Program and the suggestions related to the nurses in similar situation and to the Nursing Schools - was mailed to this group. The answers showed that the option, in spite of being determined by several circumstances, sets up a valuable experience and is part of the history of the nursing graduate programs in Brazil.

\section{DOCTORES Y DOCTORANDOS EN ENFERMERÍA: MOTIVOS PARA REALIZAR MAESTRÍAS EN OTRAS ÁREAS}

Existen, en el post grado de Brasil, 37 doctores o alumnos de doctorado en Enfermería que han realizado su Maestría en otra área. Se han obtenido declaraciones de los enfermeros de ese grupo minotitario en lo que se refiere a los motivos de esa 
elección, a su inserción en el programa frecuentado y a las sugerencias para otros enfermeros que se encuentran en esa misma situación, y a las escuelas de enfermería. La opción, aunque determinada por circunstancias diversas, se constituye una experiencia enriquecedora y hace parte de la historia de los post grado del Brasil.

TÉRMINOS CLAVES: programa de post grado, enfermeria, enseñanza

\section{ANEXO 1}

São Paulo, 28 de setembro de 1995.

Cara Doutoranda ou Doutora:

Os Programas de Doutorado em Enfermagem, no Brasil, têm revelado a presença de candidatos que obtiveram seu título de Mestre em outra área.

Este grupo ainda não foi devidamente valorizado e por sermos docentes de Programas de Pós-Graduação, despertou nosso interesse, o conhecimento da trajetória percorrida por essas colegas.

Nesse intento, obtivemos de todos os Programas de Doutorado em Enfermagem, a relação dos nomes e endereços dos colegas que preenchem tais requisitos.

Assim, estamos encaminhando a você uma solicitação para podermos estudar as características desse grupo de enfermeiros que se destacam ao cursar outro Mestrado que não de Enfermagem.

Sua contribuição é imprescindível ao estudo e será mantida no anonimato.

Desde já agradecemos a colaboração e o envio das informações no menor prazo possível.

Prof $^{a}$ Dr $^{\text {a }}$ Paulina Kurcgant

Presidente da CIPG
Prof ${ }^{a}$ Dr $^{\mathrm{a}}$ Victória Secaf

Presidente da CPG

\section{INFORMAÇÕES / RELATOS / SUGESTÕES}

(se necessário, utilize o verso desta e da outra folha)

1. Relate os motivos que a levaram a fazer o Mestrado em outra área (Não de enfermagem).

2. Especifique como se deu a sua inserção no grupo de Mestrado.

3. Como, hoje, você percebe essa experiência de Mestrado

3.1. no Doutorado em Enfermagem

3.2. na profissional

4. Face à experiência vivenciada, o que teria como sugestão:

4.1. para as Escolas de Enfermagem

4.2. para outros enfermeiros em idêntica situação à sua

\section{REFERÊNCIAS BIBLIOGRÁFICAS}

01. ALMEIDA, M.C.P. de A pós-graduação em enfermagem no Brasil situação atual. Rev.Latino.am.enfermagem, v.1, n., p.43-50, 1993.

02. CASTRO, R.A.P. de et. al. Subsídios para atualização do documento "Avaliação e perspectivas da área de Enfermagem- CNPq/1982". Acta Paul. Enfermagem, v.2, n.4, p.101-10, 1989.
03. FRAGA, M.D.N. de O. Pesquisa em enfermagem no Brasil e diferenças regionais. In: SEMINÁRIO NACIONAL DE PESQUISA EM ENFERMAGEM, 7, Fortaleza, 1994. Anais. Fortaleza: ABEn, 1994. p.87-92.

04. ONOFRE, T.M. de S.G. et al. A participação do enfermeiro assistencial nos cursos de pósgraduação. Enf.Cient., v.1, n.2, p.17-22, 1990. 
BIBLIOGRAFIA CONSULTADA

01. Augusto, D.; Adorno, F.R. Curso de especialização em enfermagem obstétrica e obstetrícia social da disciplina enfermagem obstétrica do Departamento de Enfermagem da Escola Paulista de Medicina. Acta Paul. Enfermagem, v.3, n.3, p.106-8, 1990.

02. BRASIL. Ministério da Educação. Secretaria da Educação Superior. III Plano Nacional de pósgraduação 1986-1989. Brasília, 1989.

03. CALIRI, M.H.L. O programa "sandwich" de doutorado no exterior uma experiência em enfermagem. Rev. Latino-am. enfermagem, v.1, n.1, p.43-50,1993.

04. EGRY, E.Y. A pós-graduação em enfermagem em saúde coletiva no Brasil/Editorial/ Bol.Inf.Esc.Enf.USP, v.2, n.5, p.1, 1991.

05. ENDERS, B.C. O objeto da produção científica em enfermagem na Universidade Federal do Rio Grande do Norte. Rev.Bras.Enfermagem, v.46, n.3/4, p.226-33, 1993.

06. JOUCLAS, V.M.G. et al A formação do administrador de saúde a nível de mestrado.Hosp.Adm.Saúde, v.14, n.4, p.155-63, 1990.

07. LOPES,C.M. Exames gerais de qualificação: um relato de experiências ao nível de doutorado. Rev.Esc.Enfermagem USP, v.26, n.1, p.105-18, 1992.
08. MERIGHI, M.A.B. A docência de enfermagem em uma universidade pública: um enfoque fenomenológico. São Paulo, 1983. 217p. Tese (Doutorado) - Escola de Enfermagem, Universidade de São Paulo.

09. MICHEL, J.L.M. et al. Especialistas em enfermagem médico-cirúrgica: há interesse neste profissional? Acta Paul. Enf., v.5, n.1/4, p.26-35, 1992.

10. REUNIÓN Desarrollo de Enfermeria de Latino America. Belo Horizonte: Universidade Federal de MInas Gerais, 1992

11. SECAF, V. Pós-Graduação em enfermagem/terceiro milênio. Rev. Esc. Enfermagem USP, v.29, n.1, p.8-12, 1995.

12. TREVISAN, M.A. et al. A investigação em enfermagem no Brasil. Rev.Paul.Enfermagem, v.10, n.3, p.91-5, 1991.

13. TYRREL, M.A.R. et al. Programa de pós-graduação em enfermagem da Escola Anna Nery Universidade Federal do Rio de Janeiro: inovações curriculares no curso de mestrado. Rev.Bras.Enfermagem, v.46, n.1, p.72-9, 1993. 14. UNIVERSIDADE DE SÃO PAULO. Escola de Enfermagem de Ribeirão Preto. Programa Interunidades de Pós-Graduação 1982-1992. São Paulo, 1992. 